\title{
Seasonal and longer term trends in sea temperature along the French North Sea coast, 1975 to 2002
}

\author{
Daniel Woehrling*\$ , Alain Lefebvre ${ }^{\dagger}$, Geneviève Le Fèvre-Lehoërff ${ }^{\ddagger}$ and Régis Delesmont ${ }^{\dagger}$ \\ *IFREMER Centre de Nantes, BP 21105, 4311 Nantes Cedex 3, France. 'IFREMER, Centre de Boulogne-sur-Mer, 150 quai Gambetta, \\ BP 699, 62321 Boulogne-sur-mer Cedex, France. ${ }^{\ddagger}$ IFREMER Centre de Brest, BP 70, 29280 Plouzané Cedex, France. ${ }^{\text {INSTITUT }}$ \\ PASTEUR DE LILLE Antenne de Gravelines, ZIP des Huttes - route du Colombier - 59280 Gravelines, France. \\ ${ }^{\S}$ Corresponding author, e-mail: daniel.woehrling@ifremer.fr
}

\begin{abstract}
Regular sea temperature measurements have been made since 1975 at Gravelines (French coast of the Southern Bight of the North Sea) within the framework of a research programme aimed at monitoring the influence of the thermal discharge of a nuclear power plant. The sampling has yielded a 28-year timeseries. Pluriannual natural fluctuations of temperature show cyclic patterns and long-term trends in good accordance with global climatic changes as revealed by the NAO (North Atlantic Oscillation) annual index.
\end{abstract}

\section{INTRODUCTION}

In the past few decades, climatic and hydrobiological changes have become of great interest to marine scientists, especially during recent years when unusual trends have been reported and major events have affected living resources and fishing management. Time-series have become especially important to studies of the biological influence of climatic changes, both in themselves and in providing a baseline for future investigation.

Several recent investigations have been carried out over a period of nearly three decades on the French coast of the eastern English Channel and North Sea within the framework of a research programme devoted to monitor the effects of nuclear power stations on the environment and living resources. Studies were conducted by IFREMER (Institut Français pour l'Exploitation de la Mer), as well as by several universities, including the Université de Lille (Station de Wimereux) and the Institut Pasteur de Lille (Antenne de Gravelines); additional research has been carried out by EDF (Électricité de France). The data from these sources were complemented by water temperature measurements made within the framework of the RNO (Réseau National d'Observation de la Qualité du Milieu Marin), a French national sampling network in which IFREMER is also involved. These different programmes provided the opportunity to collect an important set of data related to major ecological compartments including benthos, pelagos (zooplankton and bacteria), fishing resources, as well as hydrological parameters.

Several sites have been selected for setting up nuclear power stations along the French coast, extending through three main biogeographical regions, from the Southern Bight of the North Sea to the entrance to the English Channel. This paper focuses on Gravelines, close to the western port of Dunkirk (Figure 1), at the lower end of the Southern Bight of the North Sea, where shallow continental waters surmount emerging shoals. Gravelines has the longest time-series, with temperature measurements beginning during autumn 1974. During these years temperature measurements were regularly carried out by several research teams. It appeared of major interest to study the long-term evolution of the temperature patterns in relation to large and meso-scale events in time and space. These investigations are a first step to further ones aimed to highlight relationships between ocean climate and biological events.

\section{MATERIALS AND METHODS \\ Temperature sources and data selection}

The temperature data measured by the different research teams involved in the monitoring were collected and pooled. In order to avoid bias due to thermal discharge of the power plant, we used only values obtained at sampling points located outside the heated plume. The slight difference between surface and bottom values at selected points distant from the discharge (no stratification) shows they were clear of the plume.

Considering only a particular set of values measured at three sampling points located along a radius from the power plant respectively at $0.5,1$ and 3 miles from the shore, we tested the rate of water stratification and the difference between the most inshore point (inside the thermal plume) from 1980 onwards, and the other points. As expected, mean difference between surface and bottom temperature was very small, rarely exceeding $0.1^{\circ} \mathrm{C}$ except at the most inshore sampling point after the 1980s, at the onset of thermal discharge from the station, where heated waters stay on the surface. A Student $t$-test was performed to compare the mean difference between surface and bottom temperature measured at the same time, before (20 values) and after (55 values) 1980. The difference was highly significant at the 1.96 level, four times the standard deviation, showing that stratification at the most inshore sampling point is related to thermal discharge and that 


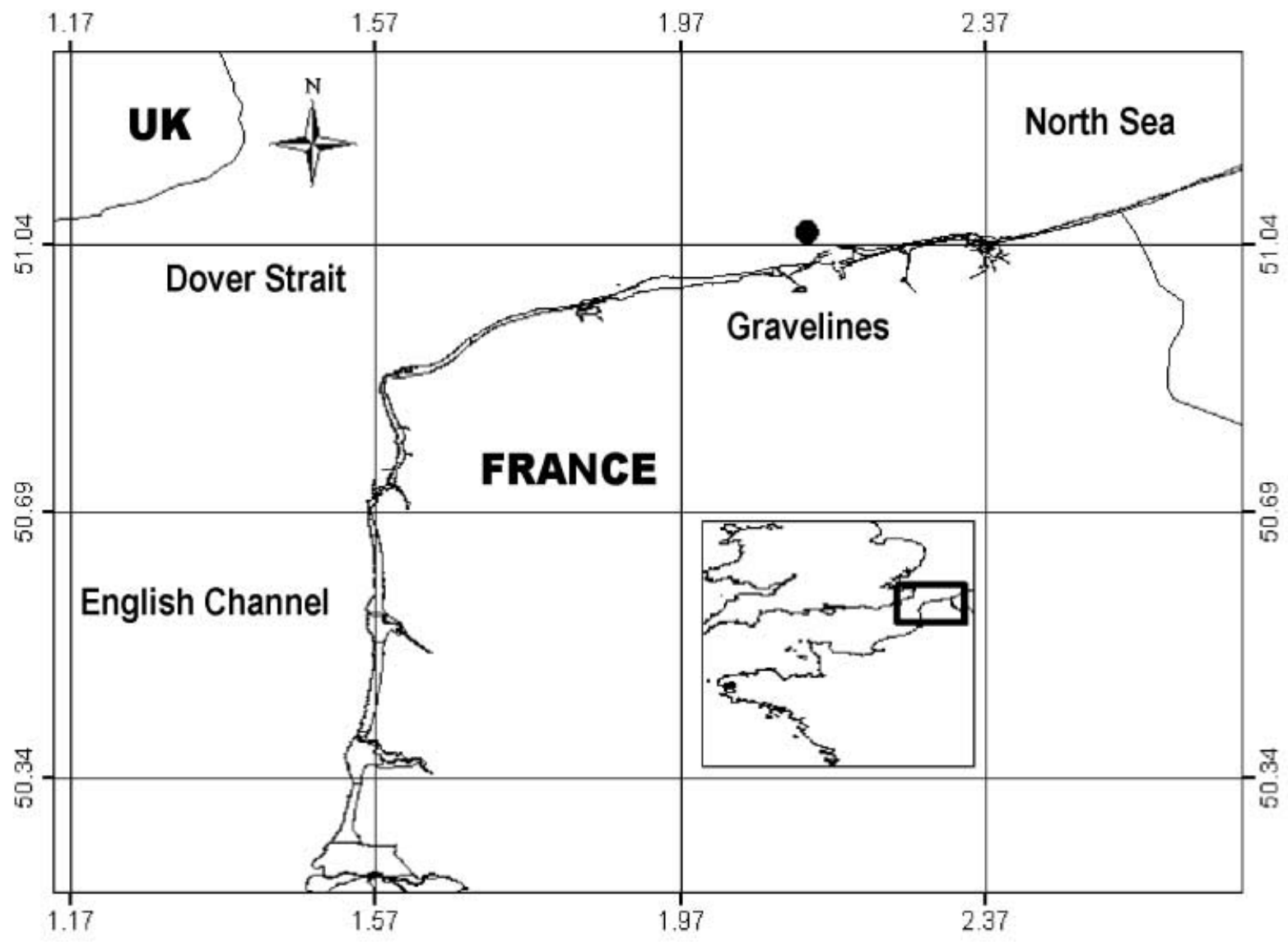

Figure 1. Location of the power plant of Gravelines in the north of France, along the coast of the North Sea Southern Bight, near the western port of Dunkirk.

neither surface temperatures at this point nor the surfacebottom mean can be included in our natural time-series; in consequence, they were discarded.

These results were complemented from 1980 to 1988 with automatic recording by immersion thermograph values gathered by EDF. As previously, only points distant from the thermal plume were retained. From 1982, temperatures obtained at the intake channel by our team and also by the Institut Pasteur de Lille (from 1984) were added to the pool of data. The data were also complemented (mainly until 1984) by the RNO measurements off Dunkirk. In this way, a great number of temperature data were collected; when several temperatures were available for a given day, the mean was used. So far 3240 values have been gathered over a period of 28 years.

\section{Data processing}

Data analyses were carried out either with raw data, before or after regularization and deseasonalization (i); or with integrated data, the latter by 'cumulative deviation' calculation (ii); or degrees-days calculation (iii). Measured data were then compared to the NAO winter index (iv).

\section{Statistical analyses on raw data}

All statistical processing used PASTECS (Package for Analysis of Space-time Ecological Series) developed for the French PNEC (Programme National d'Environnement Côtier) ART 4 (Action de Recherche Thématique-4) program. The PASTECS is freely downloadable from http://www.sciviews.org/pastecs. Different graphical and statistical analyses were performed to quantify major trends at different temporal scales.

The first analysis, at the seasonal scale, was a graphic depiction of the 28 years data for each variable grouped by month using 'box-and-whisker' plots. The central horizontal line of the box is the median of the data, the top and the bottom of the box are respectively the 25th and 75th percentiles (quartiles), and the ends of the whiskers corresponded to 1.5 times interquartile distance.

Long time series often have irregular sampling and missing values, data distribution functions different from the normal, and high variability. Our time series was regularized using Spline function (Lancaster \& Salkauskas, 1986). As we considered the time series to be composed of three additive elements - the long-term trend, the seasonal variation and the residuals - the series was filtered to remove seasonal variability using the Lowess method, a local polynomial regression (Cleveland et al., 1990). Finally, seasonal Kendall- $\tau$ analysis was performed on deseasoned series to test for monotonic trend (Hirsch et al., 1991).

The seasonal Kendall- $\tau$ test is a non-parametric regression analysis which determines direction of trend $(+$ or -$)$, goodness of fit $(\tau)$, statistical significance of fit (the $P$-value) not accounting for serial correlation. Reversal in trend direction, such as might be seen in the case of interannual oscillations, cannot be detected by this analysis. Statistical significance was set at $P<0.05$. 


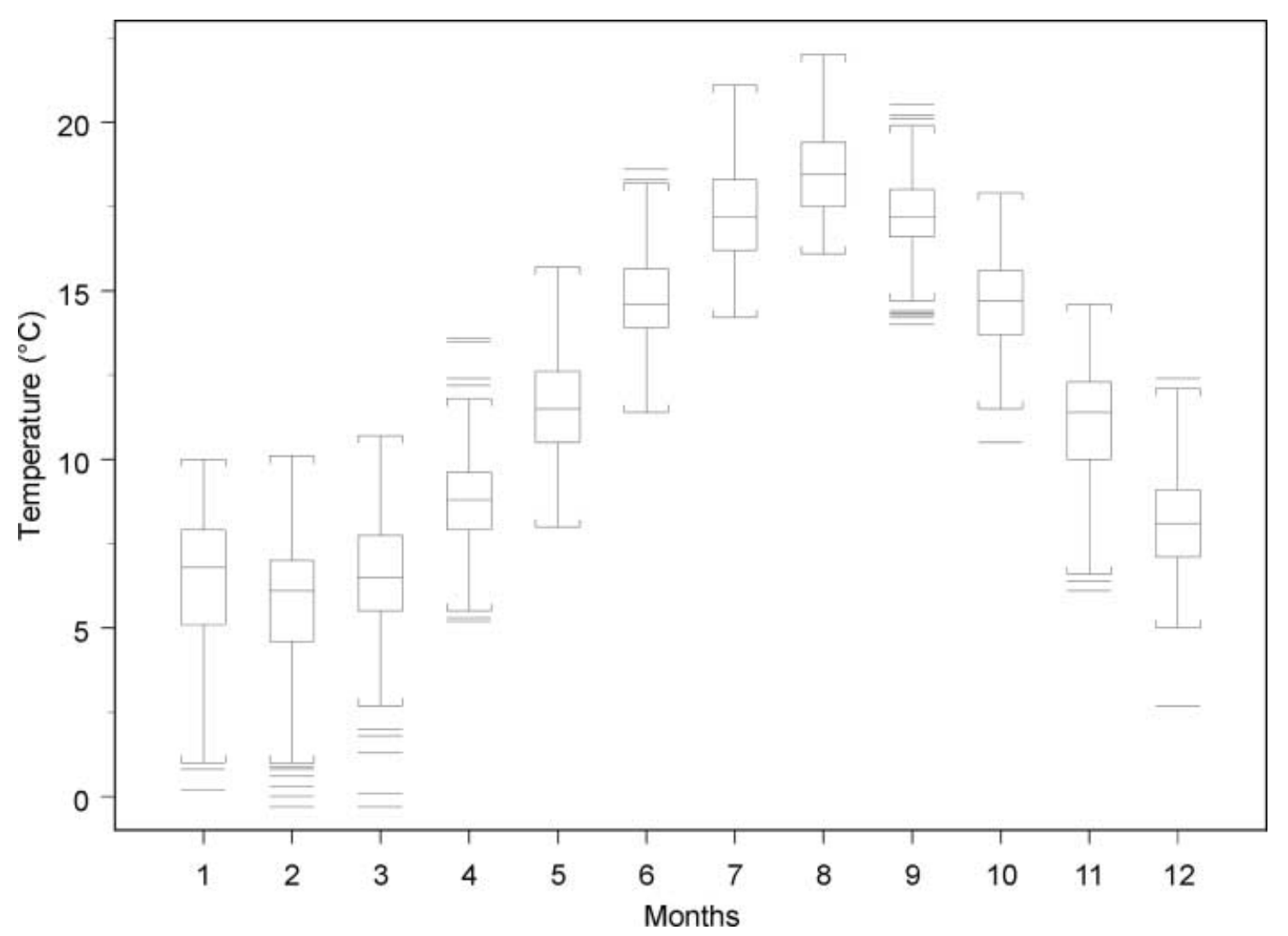

Figure 2. Temperature data grouped for each month over 28 years; 'outliers' show a rather high annual variability.

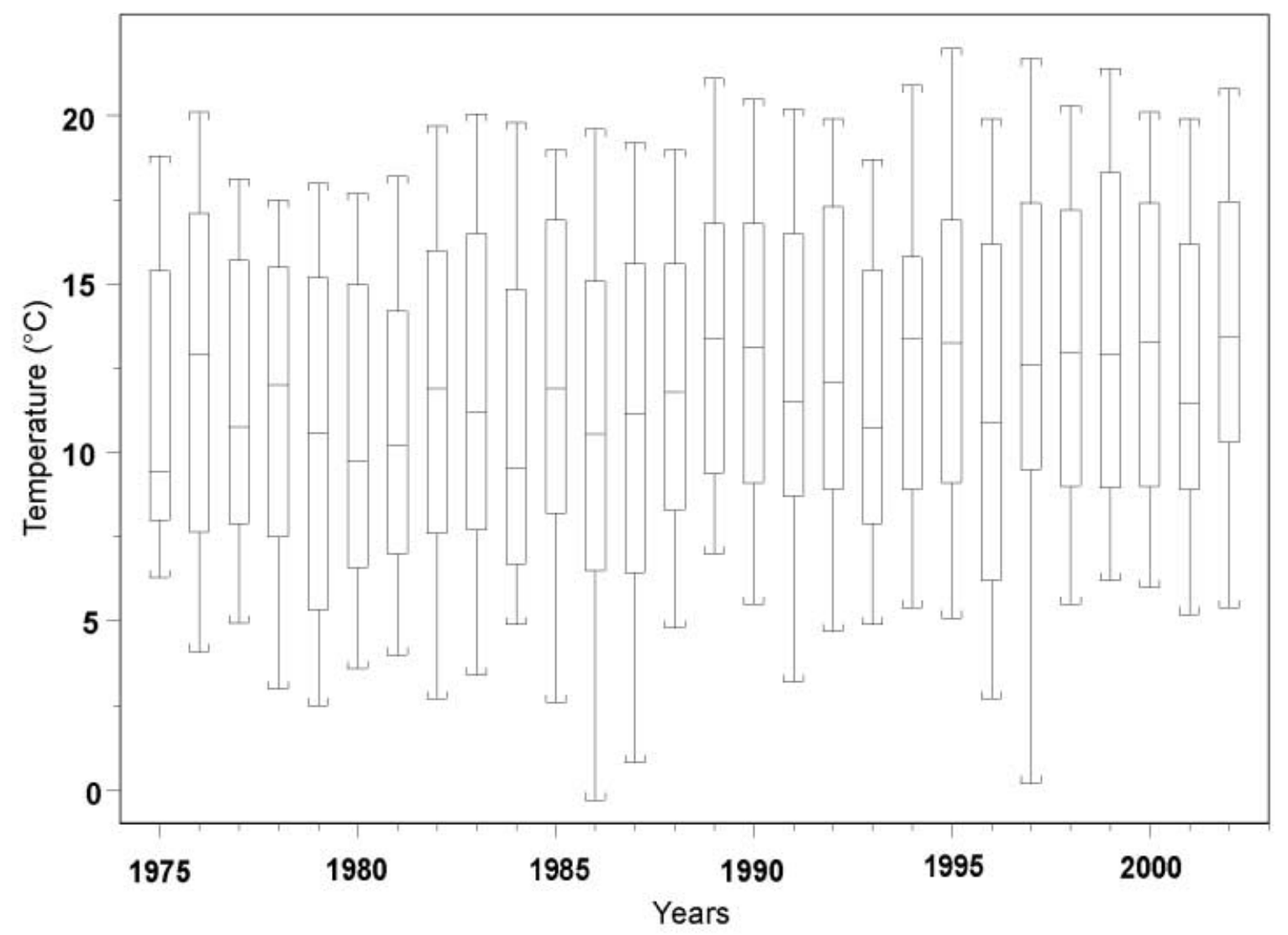

Figure 3. Temperature data at Gravelines from 1975 to 2002. Values are grouped for each year. 
To test the correlation between the degrees-days of temperature and the NAO index (see further), we used a linear regression model where the degrees of freedom $(\mathrm{df})$ in the statistical test were adjusted to avoid bias due to autocorrelation in the data. In this we followed Fox et al. (2000) who applied the equation proposed by Chelton (1984) modified by Pyper \& Peterman (1998):

$\frac{1}{\mathcal{N}^{*}}=\frac{1}{\mathcal{N}}+\frac{2}{\mathcal{N}} \sum_{j} r_{x x}(j) r_{y y}(j)$

where $\mathcal{N}^{*}$ is the number of independent joint observations on the time-series $X$ and $Y, \mathcal{N}$ is the sample size and $r_{x x}(j)$ and $r_{y y}(j)$ are the autocorrelation of $X$ and $Y$ at lag $j$.

\section{Cumulative deviation treatment}

This calculation refers to a method used in the field of industrial control and transposed by Ibanez to the study of chronological data in oceanography (Ibanez et al., 1993). It consists of subtracting a reference value (here the mean of the considered series) from the data, the residuals being then successively added. Successive negative residuals produce a decreasing slope whereas successive positive residuals produce an increasing slope; a regular increasing trend starting from a negative residual, as in our series, produces an U-shape curve and the lower part of the $\mathrm{U}$ corresponds to the geometric middle of the series (half the number of values).

This cumulative function reveals main changes that are not evident and often hidden in the raw data curves, especially when the latter show numerous fluctuations without evident structure. This method, which is very simple and requires no special condition for its application, allows processing of data with missing values; it does not claim to be a model, but provides a robust way of highlighting major events in order to suggest further lines of analyses.

\section{Degrees-days treatment}

The degrees-days (DD) calculation offers a useful method to overcome short-term temperature fluctuations that render seasonal variations confusing. This parameter appears to be of marked biological significance, assuming that the biological influence of temperature depends also on time and not only on instantaneous values. Physically, the DD amount is comparable with a quantity of stored energy and can be considered as a synthetic and conservative parameter actually involved in physiological responses.

The DD amounts between two successive sampling dates were found by trapezoidal integration and cumulated. Monthly DD amounts were therefore calculated by difference between values of cumulated DD at the beginning of two successive months; when no temperature measurements were available at these times, integration was done after calculation of the lacking temperature(s) by interpolation of the surrounding values. The deviations from the DD mean for each month were then plotted against time to restore a more obvious time-series.

Another times-series was obtained by cumulating the yearly DD amount or the winter DD amount (from December to March), plotted versus time and compared with the evolution of the NAO winter index (see here below).

\section{$\mathcal{N} A O$ index}

The North Atlantic Oscillation (NAO) is the dominant mode of winter climate variability in the North Atlantic region. The NAO is a large scale seesaw in atmospheric mass between the subtropical high and the polar low. Several indices have been developed to quantify the state of the NAO as a climatic index, but the most widely used is Hurrell's NAO index which computes the normalized sea level pressure difference based on measurements from Lisbon, Portugal and Stykkisholmur/Reyjavik, Iceland from December to March (Hurrell, 1995). This winter NAO index was obtained from the internet site http:// www.met.rdg.ac.uk/cag/NAO/index.html

\section{RESULTS}

The water temperature at Gravelines exhibits different features resulting from several patterns depending on the time scale considered. The seasonal cycle is affected by long-term general trends and cyclic patterns, these major structures being disrupted by exceptional events and short-time fluctuations.

\section{Seasonal variations}

The annual thermal amplitude from the winter minimum (mainly in February, generally about $5^{\circ} \mathrm{C}$ ) to the summer maximum (mainly in August, generally about $18^{\circ} \mathrm{C}$ ) ranges between 12 and $20^{\circ} \mathrm{C}$; the maximal amplitude was observed in 1997 where temperatures fell to $0.2^{\circ} \mathrm{C}$ at the beginning of January and rose up to $21.7^{\circ} \mathrm{G}$ in August. The minimum winter temperature $\left(-0.3^{\circ} \mathrm{C}\right)$ was observed at the end of February 1986 and the summer temperature reached $22^{\circ} \mathrm{C}$ in August 1995. Thus, yearly fluctuations at a given time of the seasonal cycle may be high and it comes as no surprise that when grouping the values on a same annual variation graph, it exhibits great variability, especially during winter and early spring (Figure 2) when yearly variability is higher than in summer.

\section{Yearly fluctuations}

When analysing the raw data (Figures $3 \& 4$ A) a few exceptional values emerge: low winter minima, 1986 and 1987 (respectively $-0.3^{\circ} \mathrm{C}$ and $1^{\circ} \mathrm{C}$ ), 1996 and 1997 (respectively $3^{\circ} \mathrm{C}$ and $0.2^{\circ} \mathrm{C}$ ), and to a less extent 1978 and 1979 (respectively $3^{\circ} \mathrm{C}$ and $2.5^{\circ} \mathrm{C}$ ); and high summer maxima, $1989\left(21.1^{\circ} \mathrm{C}\right), 1995\left(22^{\circ} \mathrm{C}\right), 1997\left(21.7^{\circ} \mathrm{C}\right)$, and to a less extent $1976\left(20.1^{\circ} \mathrm{C}\right)$ and $2002\left(20.4^{\circ} \mathrm{C}\right)$. Except for these particular years, winter minima and summer maxima have been generally higher since the 1990s than before, as also the annual mean (Figure 3). This major tendency emerges from the monthly (Figure 5) or, more evidently, from the yearly DD amounts (Figure 8), distinguishing two main periods, before and after 1988. Thus high summer values became more common after 1988 with only a few exceptional warm years before 1988 (1976, 1982, 1983). The whole time-series shows a rough tendency to an increase in mean temperature, with a major change around 1988. Indeed, the results of the Kendall- $\tau$ test shows a significant positive monotonic trend in temperature for the period from 1974 to 2002 


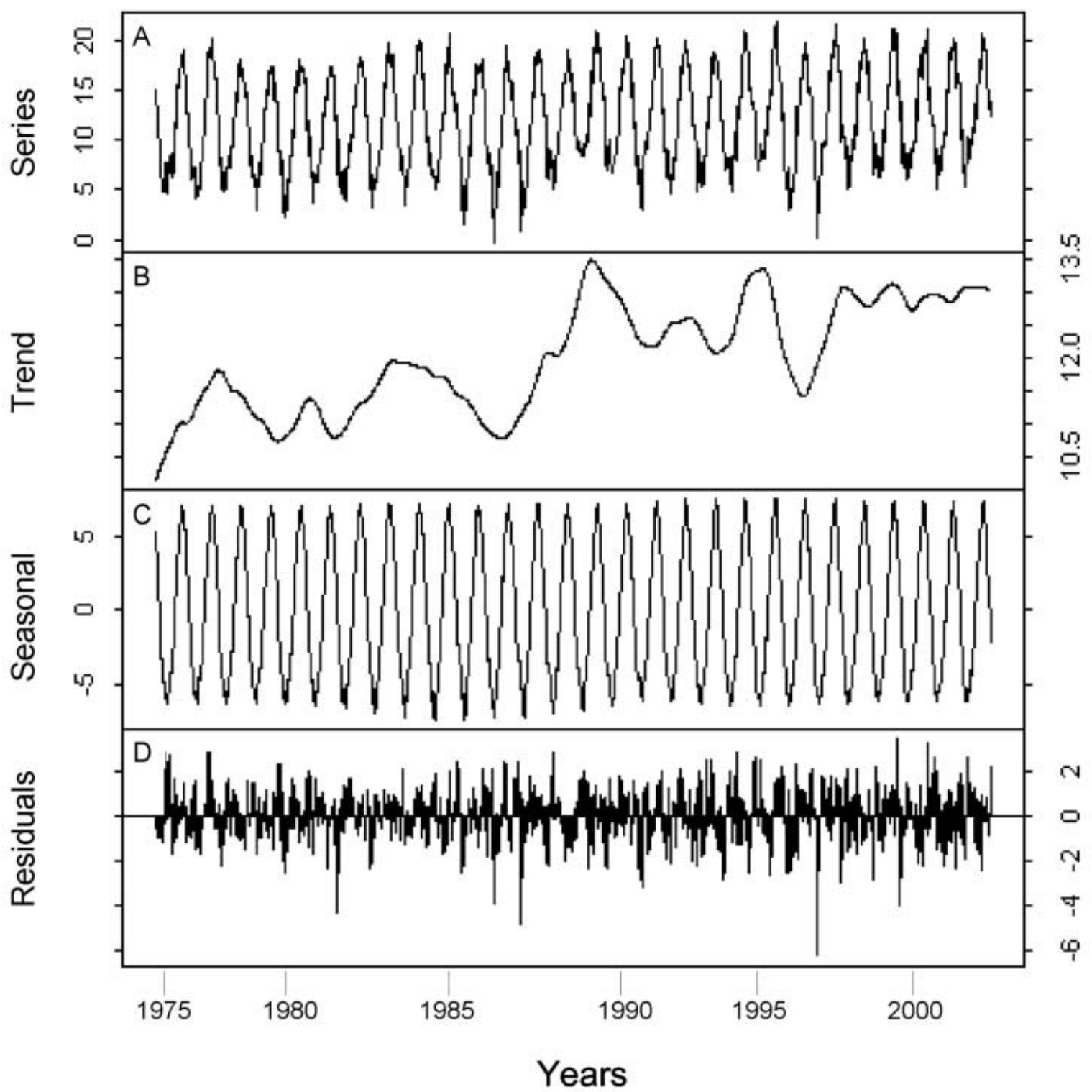

Figure 4. Decomposition of the main variability sources on the temperature time-series of Gravelines: (A) raw temperature data (about 3200 measurements); (B) tendencies; (C) seasonal cycle; (D) residuals.

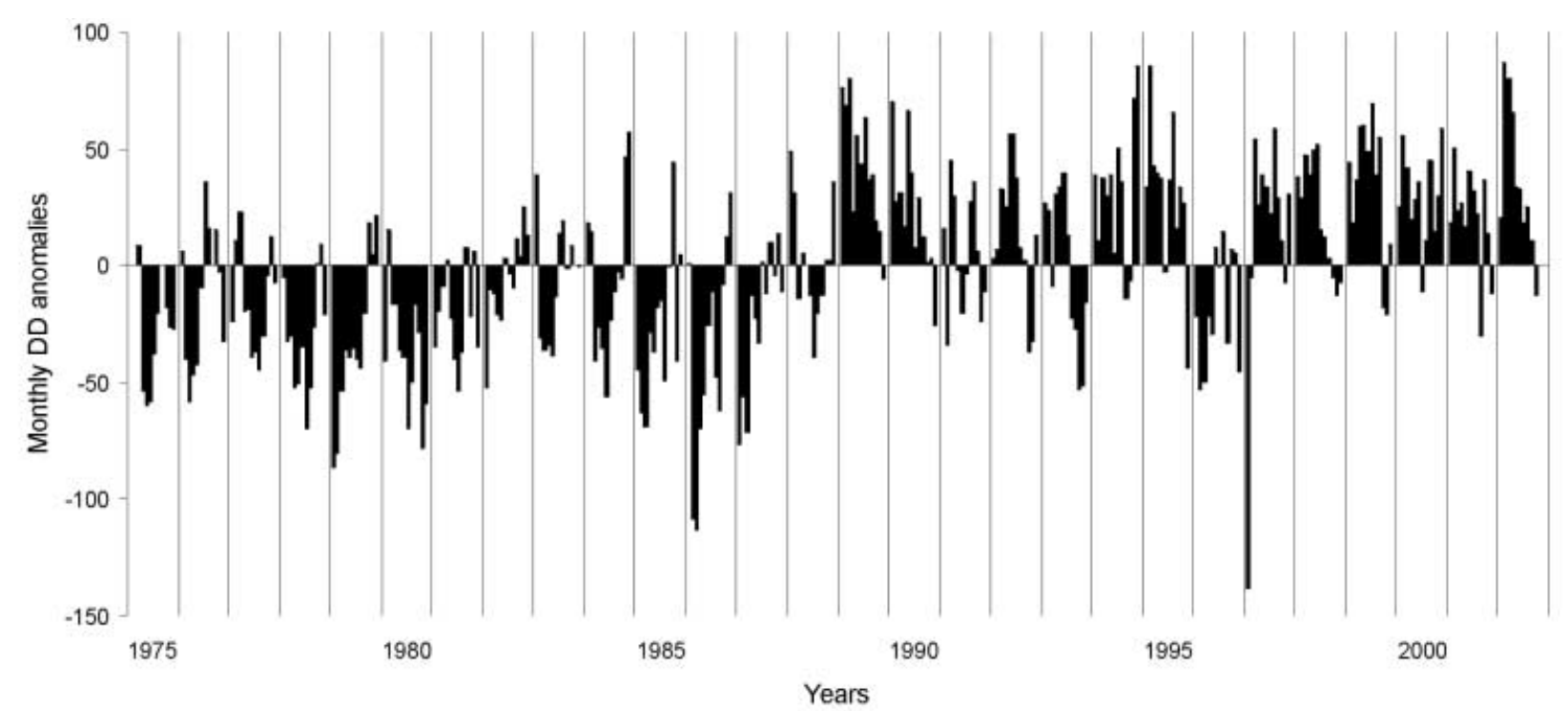

Figure 5. Degrees-days anomalies (deviation from the mean amount for each month over 28 years) from 1975 to 2002. 


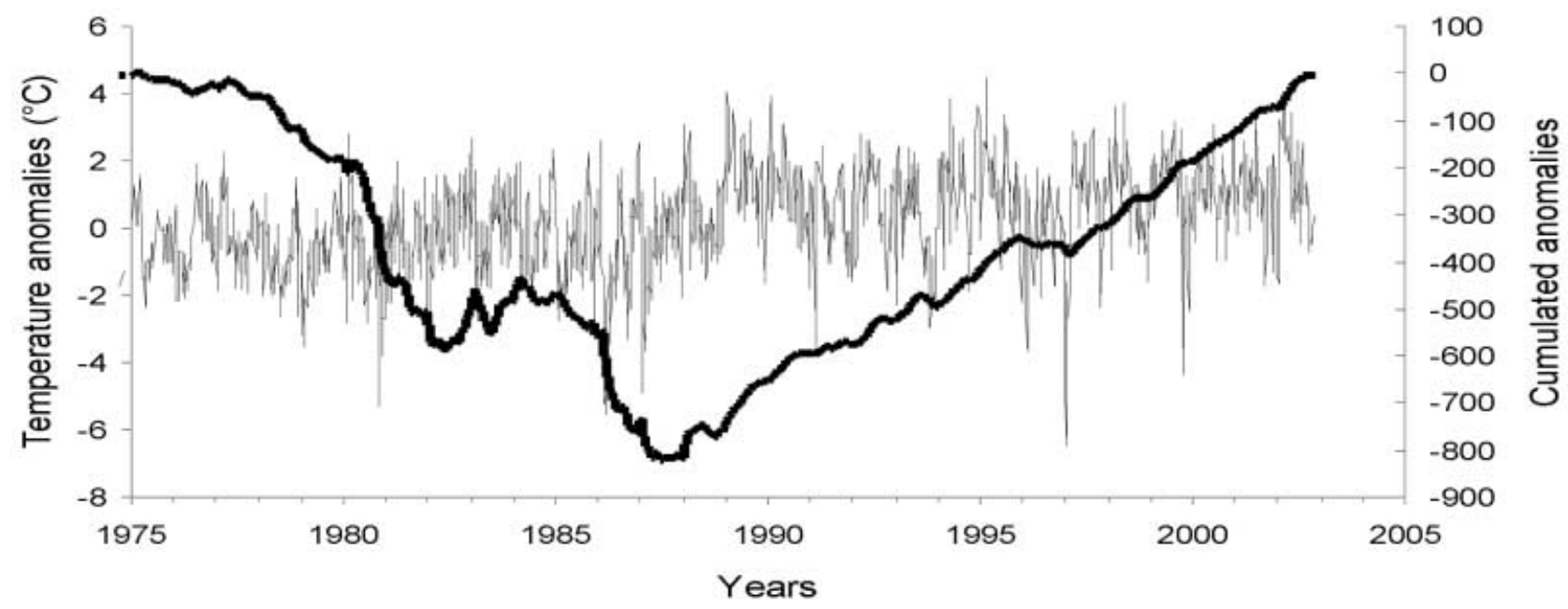

Temperature anomalies Cumulative deviation

Figure 6. Temperature anomalies at Gravelines from 1975 to 2002 (raw data and cumulative deviation). This particular 'CumSum' curve is obtained by simply adding successively the raw anomalies without previous subtracting the mean of the series which is of course zero.

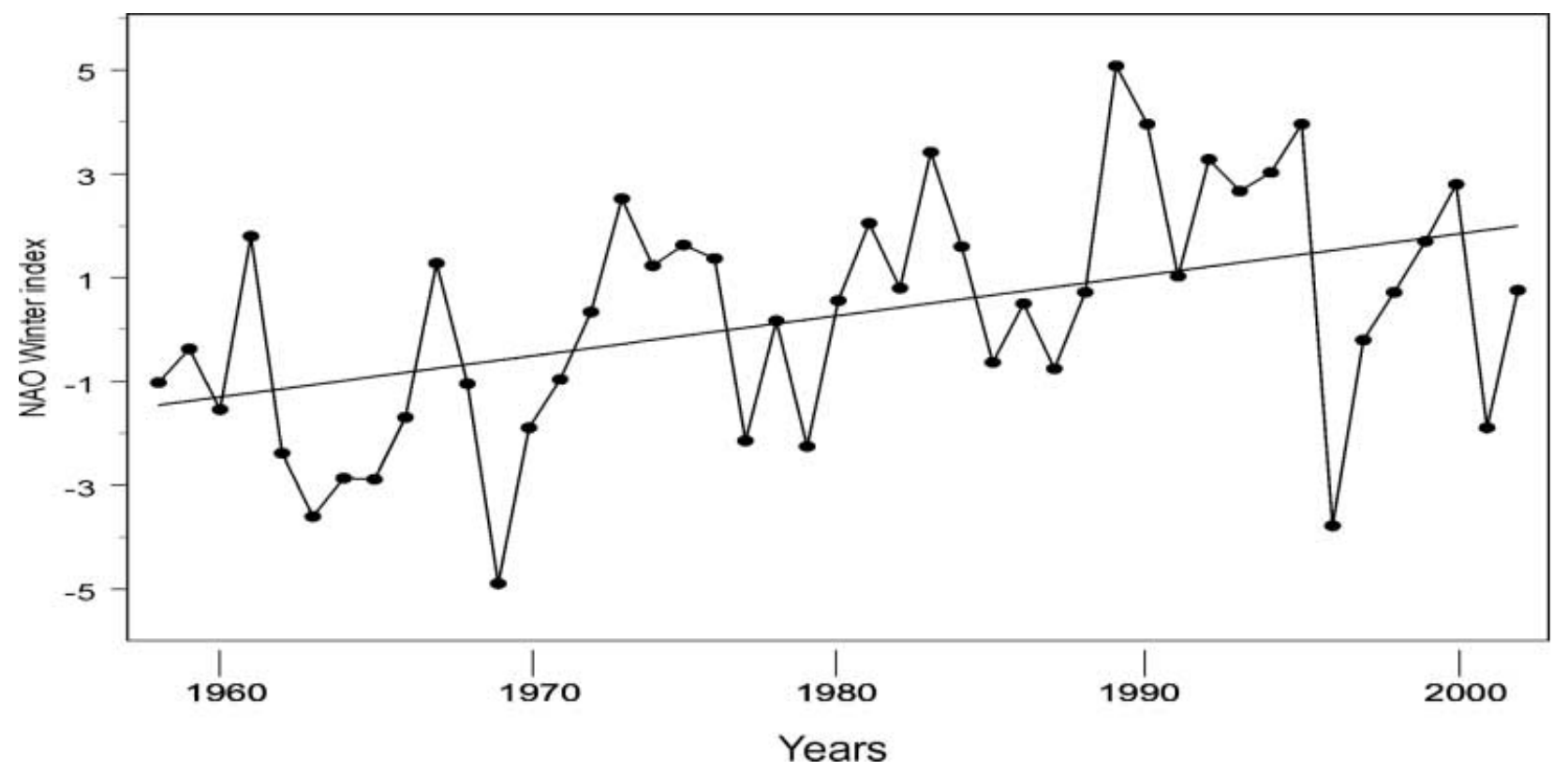

Figure 7. Winter NAO (North Atlantic Oscillation) index (December-March) from 1958 to 2002 with linear tendency.

$\left(\tau\right.$-value $=+0.05$ and $P$-value $\left.=6 \times 10^{-4}\right)$. This tendency shows a more complex pattern after subtraction of the seasonal component from the raw data (Figure 4A).

Another feature revealed by Figure 3 is the slight pluriannual oscillation exhibiting an average period of 7-8 years, also visible in Figure 4A.

The cumulated deviation ('CumSum') method applied on raw data (deviations from the mean temperature observed for a given day throughout the 28 years) may reveal other periods of major changes (Figure 6). Obviously, the global U-shape of the curve is characteristic of a general trend for increasing temperatures from the beginning to the end of the series, the major event being situated around 1988 at the inversion of the balance between negative and positive residuals and is not due to an artefact, this period not being situated at the centre line of the series.

The period 1982-1985 marks a disrupting of the negative slope during the first part of the curve, due to less cold winters and relative warm summers; the strong negative slope of the curve around this episode, during 1980-1981 and 1986-1987, seems related to exceptional cold winters as revealed by the other figures (Figures 3, 4A \& 5).

To show connections with large-scale space-time phenomena, we compared the long-term trend of water temperature at Gravelines with the NAO index. Figure 7 shows the NAO winter (December-March) index with its main tendency to increasing values since the 1960s with a rising frequency of positive deviations. Fluctuations of this index for the years 1975 to 2002 have been compared with 


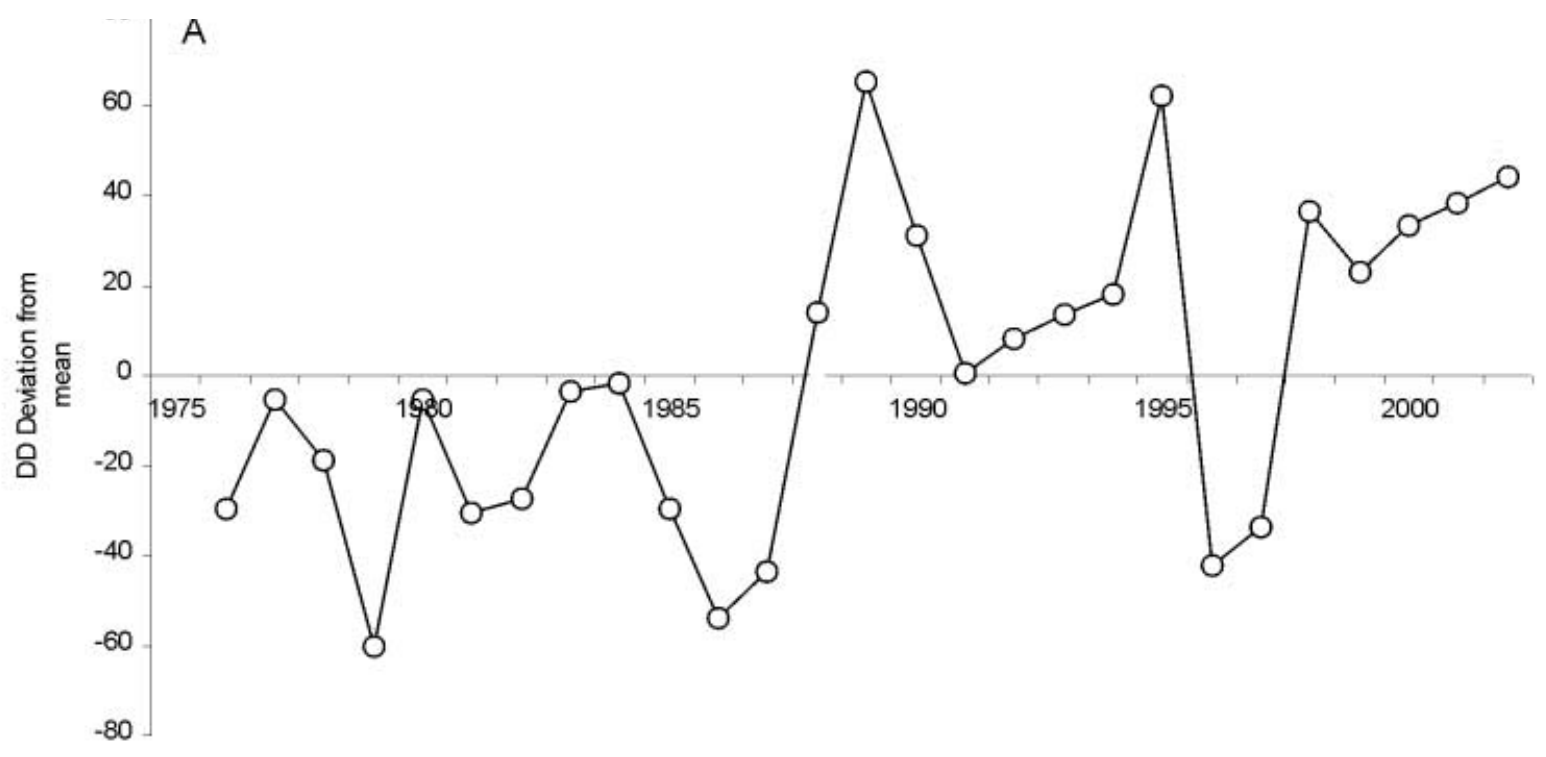

Yearly deviations -0 - December-March deviations

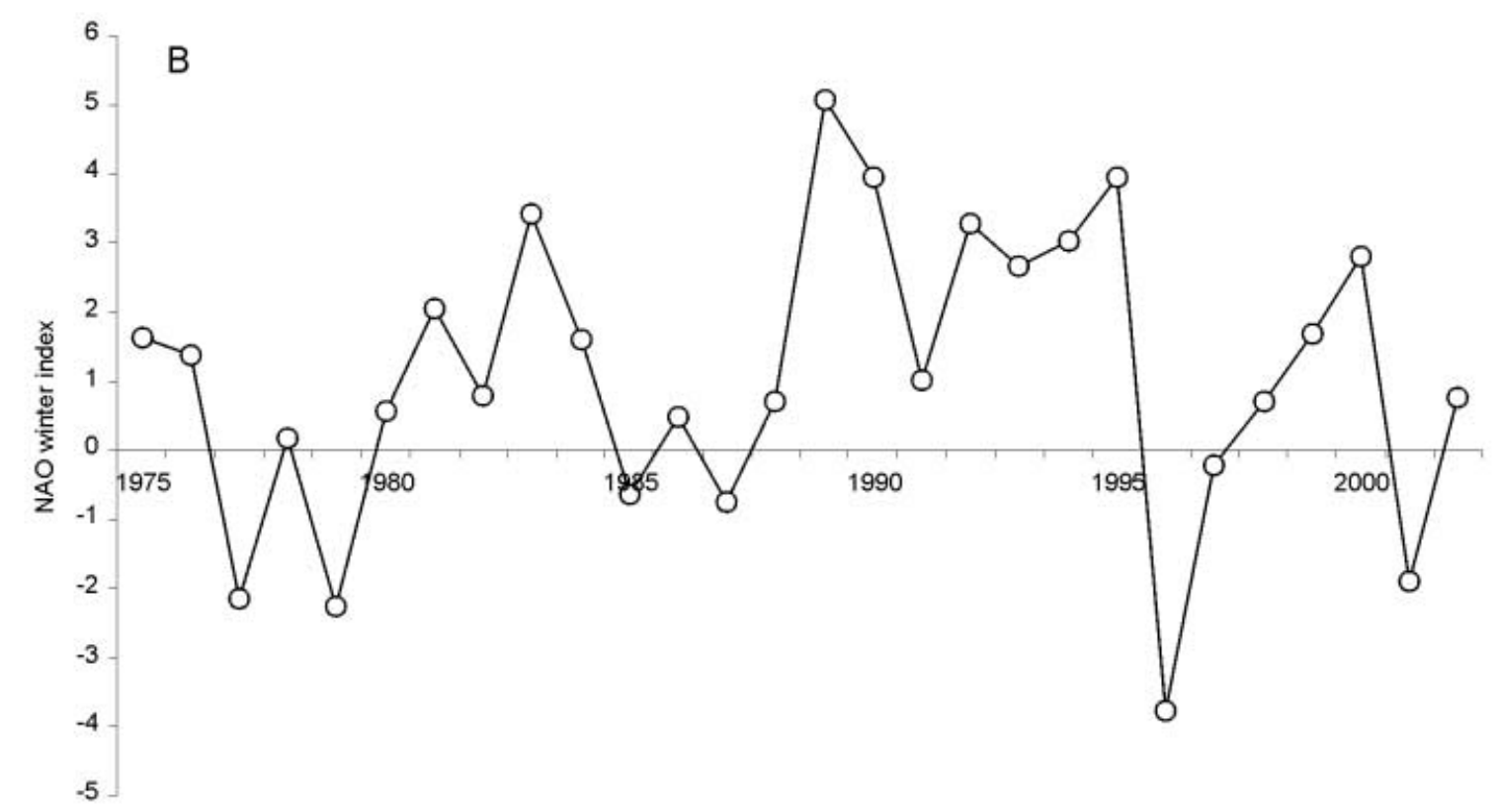

Figure 8. Comparison between $(\mathrm{A})$ the degrees-days deviations from the mean amount of the year or for the period DecemberMarch; and (B) the NAO winter (December-March) index. Compare with the tendency extracted from the raw time-series (Figure 4B).

the DD deviations from the mean, considering either yearly values, or the December-March values (Figure 8).

The similarity between the two curves suggests a link between each times-series and the NAO index. After processing linear regressions as described above, correlations for NAO index versus annual DD anomalies and December-March DD anomalies (Figure 9) had respective values of $r=0.53$ and $r=0.59(P<0.01)$. With $\mathcal{N}^{*}=24$ $(\mathcal{N}=26)$ and $\mathrm{df}=22$, the critical value of $r$ is 0.515 at $\alpha=0.01$ threshold. In both cases, $r$ is significant and the probability is less than $1 \%$ for chance correlation. Although only $30 \%$ of the total standard error can be explained by the regression, the results are remarkable and the coincidence between the curves in Figure 8 are too noticeable to be dismissed.

\section{DISCUSSION}

\section{Short-term and seasonal variability}

The biogeographical and physical characteristics of the shallow waters of Gravelines lead to much short-period variability of water temperature. These short-term fluctuations are related to the tidal cycle and air temperature changes (Woehrling \& Le Fèvre-Lehoërff, 1998).

They also affect the annual amplitude of the seasonal temperature cycle which naturally follows a northward gradient starting from the Western Channel, and is therefore emphasized in this very inshore area. In a previous paper we compared the very fluctuating system of Gravelines to the more inertial system in the Western Channel (Le Fèvre-Lehoërff et al., 1993). 

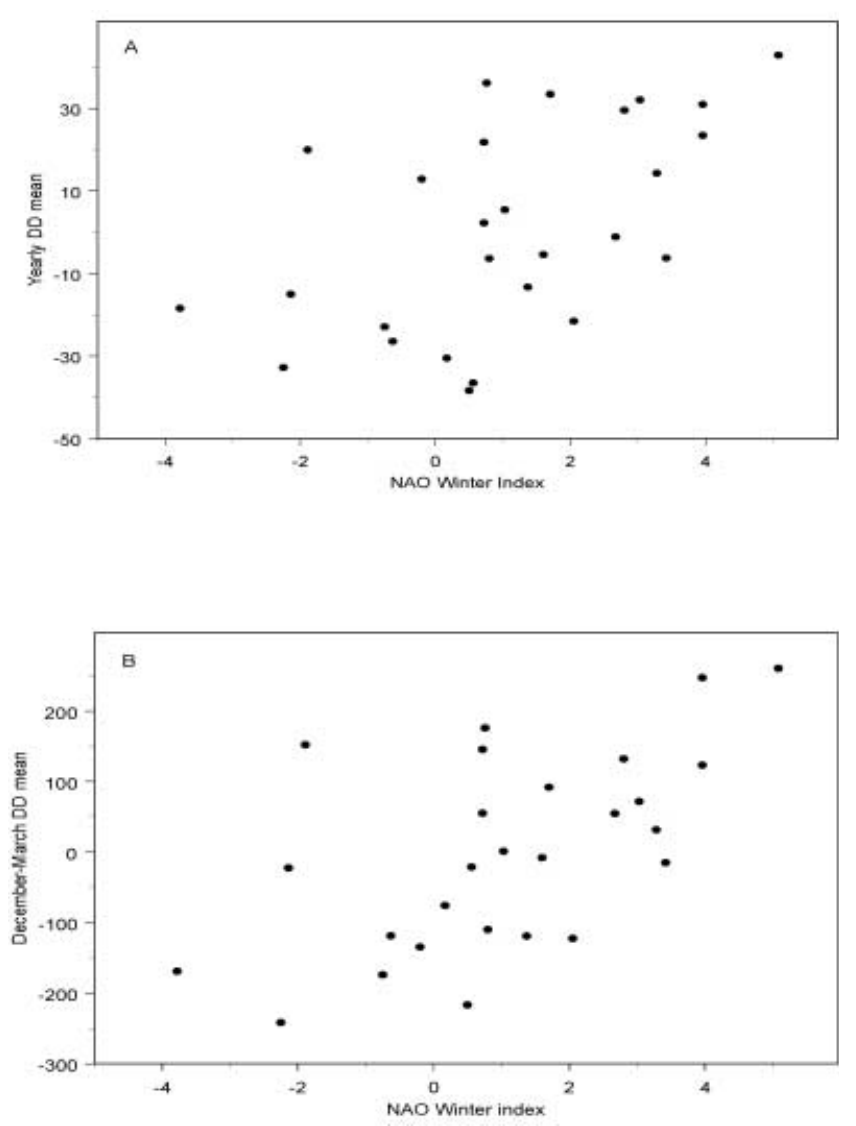

Figure 9. Correlations between (A) deviations from early DD mean; and (B) NAO December-March index.

\section{Pluriannual variability}

Superimposed on this variability at a short-time level, some remarkable features emerge at the pluriannual scale, which may be coherent with: (i) some general trends; (ii) major discrepancies due to outstanding events; and (iii) cyclic patterns affecting a wider area.

\section{General trends}

The main robust feature emerging from the data set is the general trend for an increase in mean temperature, with a major change around the last decade of the 20th Century. Such a general trend is also exhibited by the winter NAO index from the 1960s (Figure 7), showing the persistence of a strong positive phase since the early 1980s (Buch et al., 2003) and especially during the 1990s as highlighted by Jones (2003). In this context, the high NAO index is concomitant with an increasing degree of westerly winds, and consequently milder temperatures over northern Europe. A similar relation was previously shown for Gravelines from wind data analysis (Le FèvreLehoërff et al., 1995). As generally accepted in the North Sea and the adjacent area of the Atlantic (Hurrell, 1995), correlation between the winter NAO index and temperature is strongest during winter. Jones (2003) and others have stated that the relation between the NAO index and tendencies in the northern areas (North Sea and Baltic Sea) should obviously be closer than in southern waters like the Bay of Biscay. More generally, cold winters were associated with lower winter NAO index, whereas high summer temperatures were associated with higher winter NAO index.

For the northern hemisphere north of $20^{\circ} \mathrm{N}$ in all seasons, most of the analysed areas indicate warmer conditions for the 1991-2000 period than during the 1961-1990 one. Yet, the recent winter NAO values during the 1990s are not anomalous compared with longer records although they appear unprecedented over the 30 -year time scale.

Reid et al. (2001) have noted a regime shift in the North Sea after 1988. Edwards et al. (2001, 2002) showed that the temporal variability in pelagic ecosystems in the North Sea has been influenced by episodic oceanographic events. Increasing NAO index coupled with evidence for an increased inflow of relatively warm Atlantic water into the North Sea via the English Channel, produced a relatively warm climate in the North Sea during the late 1980s and early 1990s period (Edwards et al., 2001).

\section{Major events}

In addition to the main shift to warmer conditions discussed above, other events are noteworthy: the cold winters at the beginning of years 1979, 1986, 1987 and 1997. The latter is also mentioned in Buch et al. (2003) and attributed to a high inflow of Polar Water despite the fact that atmospheric conditions were quite warm. These events are also to be brought together with a circadecadal cycle of the NAO as discussed below.

\section{Long-period oscillation}

The slight long-term oscillation mentioned above has been noted in previous papers as a 7-8 years' cycle (Woehrling \& Le Fèvre-Lehoërff, 1998). Such a periodic variation was also detected in other studies, e.g. analyses by Bordat (1994) of sea surface temperatures in the Bay of Biscay (with oscillations of the maxima also showing low values around 1979 and 1986-1987) and recorded at Gravelines for some zooplankton species by Le FèvreLehoërff et al. (1995). These results are linked to meteorological features along the coast (Fromentin \& Ibanez, 1994) exhibiting a 90-96 months' cycle in air temperature for several French coastal areas (including Dunkirk, close to Gravelines), highlighting the same years for low values. Two explanations for the 7-8 years' cycle were offered by the authors, none having their preference: (1) it may represent an harmonic of a larger period of 80 to 96 years depending on locations and revealed after spectral analysis; and (2) it may be related to a phenomenon known as the polar tide, which also has a period of seven years.

Periodic oscillations are also exhibited by the NAO index (Figure 7); Ottersen et al. (2003) mention that the linking mechanisms between large-scale physical phenomena with cyclic patterns and time-series in oceanography are far from well established. In the decadal region, the influence of the 11-year sunspot cycles was discussed by earlier authors (Izhevskii, 1964; Southward et al., 1975) but shows no convincing correlation with the NAO index. The nodal tide with a period of 18.61 years due to the declination of the Moon's orbit is generally considered to be an important feature of the tidal components acting on the interannual and interdecadal time scale (Ottersen et al., 2003). The spectral peak around eight years found in some temperature series shows up in 
the MESA (maximum entropy spectrum analysis) of the NAO index but contains only $5.3 \%$ of the total variance (Ottersen et al., 2003) although it appears as the second most variant peak.

In conclusion, it comes as no surprise that the rather complex pattern of sea temperature fluctuations and evolution in the coastal area of Gravelines (Southern Bight of the North Sea) may be explained by the superposition of general features and trends affecting large areas on local conditions introducing some discrepancies, the figures depending on the scale of time and space considered. It can be noteworthy that despite a large spectrum of factors involved in local variability, a rather consistent structure arises and reveals responses to major features, events and tendencies affecting a large area over the northern Atlantic, North Sea and adjacent waters as expressed by the NAO index. However, NAO should not be invoked as the only or even the main control on ocean variability; other factors like circadecadal cycles previously reported may also contribute to the global pattern. All these general trends may yet be locally disrupted by short-scale fluctuations such as daily variability powered mainly by tidal cycles and local conditions, spoiling the long-term correlations. At the very least, it would have been surprising that such inshore and variable waters had displayed a more highly significant response to large-scale phenomena.

Besides, it may be noticeable that the rather rough timeseries with a relatively irregular time-space sampling frame can yield suitable results in good agreement with observations at a larger scale of time and space and therefore act as mirror features of general patterns. Very local observations, when repeated, may therefore deserve consideration for more extended monitoring frames.

Further investigations on such long-time series will be needed to improve that hydroclimatic forcing and oceanic influence may play a role in the control of the variability of phytoplankton and zooplankton in the eastern English Channel-Southern Bight of the North Sea.

Several papers have been published concerning changes in marine ecosystem and fisheries stocks in relation to environmental factors. Long term fluctuations of commercial fish catches, especially important changes, have been linked to climatic events and temperature evolution (Cushing, 1961; Russell et al., 1971; Southward et al., 1975, 1995; Cushing \& Dickson, 1976; Southward, 1980; Hawkins et al., 2003).

As Edwards et al. (2001) suggest for the North Sea, the degree of coupling between the atmosphere and ocean and the full extent of its influence on the variability of physical, chemical and biological parameters in the eastern English Channel-Southern Bight of the North Sea is still to be solved. The next step will be to investigate such links with biological descriptors at Gravelines.

The data related to this study were collected within the framework of the multidisciplinary research programme IGA (Impact des Grands Aménagements) conducted by IFREMER (Institut Français de Recherches pour l'Exploitation de la Mer) with financial support from the EDF (Électricité de France). Additional temperature records were directly supplied by EDF from thermograph measurements and the Institut Pasteur de Lille which provided weekly temperature measurements from 1986 onwards.
The authors wish to acknowledge the assistance from all colleagues involved in at-sea data collection and sampling surveys, laboratory studies, data analyses and capture from the onset of these studies in 1975 to the present.

Thanks to Benjamin Planque and Olivier Le Pape for valuable advice, and especially to Alan J. Southward for detailed reading of the manuscript and many valuable suggestions and corrections.

\section{REFERENCES}

Bordat, D., 1994. Analyse des séries chronologiques des paramètres hydroclimatiques du golfe de Gascogne. Internal Report IFREMER.

Buch, E., Nielsen, M.H. \& Pedersen, S.A., 2003. On the coupling between climate, hydrography, and recruitment variability of fishery resources off West Greenland. ICES Marine Science Symposia, 219, 231-240.

Chelton, D.B., 1984. Commentary: short-term climatic variability in the North-east Pacific Ocean. In The influence of ocean conditions on the production of salmonids in the North Pacific (ed. W. Pearcy), pp. 87-99. Corvallis: Oregon State University Press.

Cleveland, R.B., Cleveland, W.S., McRae, J.E. \& Terpenning, I., 1990. STL: a seasonal-trend decomposition procedure based on loess. Fournal of Official Statistics, 6, 3-73.

Cushing, D.H., 1961. On the failure of the Plymouth herring fishery. Journal of the Marine Biological Association of the United Kingdom, 41, 799-816.

Cushing, D.H. \& Dickson, R.R., 1976. The biological response in the sea to climatic changes. Advances in Marine Biology, 14, $1-122$.

Edwards, M., Beaugrand, G., Reid, P.C., Rowden, A.A. \& Jones, M.B., 2002. Ocean climate anomalies and the ecology of the North Sea. Marine Ecology Progress Series, 239, 1-10.

Edwards, M., Reid, P.C. \& Planque, B., 2001. Long-term and regional variability of phytoplankton biomass in the northeast Atlantic (1960-1995). ICES Journal of Marine Science, 58, 39-49.

Fox, C.J., Planque, B.P. \& Darby, C.D., 2000. Synchrony in the recruitment time-series of plaice (Pleuronectes platessa L.) around the United Kingdom and the influence of sea temperature. Journal of Sea Research, 44, 159-168.

Fromentin, J.M. \& Ibanez, F., 1994. Year-to-year changes in meteorological features of the French coast during the last half century. Examples of two biological responses. Oceanologica Acta, 17, 285-296.

Hawkins, S.J., Southward, A.J. \& Genner, M.J., 2003. Detection of environmental change in marine ecosystem - evidence from the western English Channel. Science of the Total Environment, 310, 245-256.

Hirsch, R.M., Alexander, B. \& Smith, R.A., 1991. Selection of methods for the detection and estimation of trends in water quality. Water Resources Research, 27, 803-813.

Hurrell, J.W., 1995. Decadal trends in the North Atlantic Oscillation: regional temperatures and precipitation. Science, New York, 269, 241-258.

Ibanez, F., Fromentin, J.M. \& Castel, J., 1993. Analyse de la méthode des sommes cumulées à l'analyse des séries chronologiques en océanographie. Comptes Rendus de l'Académie des Sciences, 316, 745-748.

Izhevskii, G.K., 1964. Forecasting of oceanological conditions and the reproduction of commercial fish. Moskow: Moskva Pishcepromidzdat.

Jones, P.D., 2003. The decade of the 1990s over the Atlantic in comparison with longer instrumental and paleoclimatic records. ICES Marine Science Symposia, 219, 25-31.

Lancaster, P. \& Salkauskas, K., 1986. Curve and surface fitting. England: Academic Press. 
Le Fèvre-Lehoërff, G., Erard-Le Denn, E. \& Arzul, G., 1993. Planktonic ecosystems in the Channel. Trophic relations. Oceanologica Acta, 16, 661-670.

Le Fèvre-Lehoërff, G., Ibanez, F., Poniz, P. \& Fromentin, J.M., 1995. Hydroclimatic relationships with planktonic times-series from 1975 to 1992, in the North Sea off Gravelines, France. Marine Ecology Progress Series, 129, 269-281.

Ottersen, G., Loeng, H., Adlandsvik, B. \& Ingvaldsen, R., 2003. Temperature variability in the Northeast Atlantic. ICES Marine Science Symposia, 219, 86-94.

Pyper, B.J. \& Peterman, R.M., 1998. Comparison of methods to account for autocorrelation analyses of fish data. Canadian Fournal of Fisheries and Aquatic Sciences, 55, 2127-2140.

Reid, P.C., Borges, M. \& Svenden, E., 2001. A regime shift in the North Sea circa 1988 linked to changes in the North Sea horse mackerel fishery. Fishery Research, 50, 163-171.

Reid, P.C. \& Planque, B., 2000. Long-term planktonic variations and the climate of the North Atlantic. In The ocean life of atlantic salmon (ed. D. Mills), pp. 151-169. Oxford: Blackwell Science, Fishing News Books.
Russell, F.S., Southward, A.J., Boalch, G.T. \& Butler, E.I., 1971. Changes in biological conditions in the English Channel off Plymouth during the last half century. Nature, London, 234, 468-470.

Southward, A.J., 1980. The western English Channel-an inconstant ecosystem? Nature, London, 285, 361-366.

Southward, A.J., Butler, E.I. \& Pennycuick, L., 1975. Recent cyclic changes in climate and abundance of marine life. Nature, London, 253, 714-717.

Southward, A.J., Hawkins, S.J. \& Burrows, M.T., 1995. Seventy years observations of changes in the distribution and abundance of zooplankton and intertidal organisms in the western English Channel in relation to rising sea temperature. Fournal of Thermal Biology, 20, 127-155.

Woehrling, D. \& Le Fèvre-Lehoërff, G., 1998. Long-term series in ichthyoplankton: sole and sprat at French coast of the North Sea from 1975 to 1994. Oceanologica Acta, 21, 113-121.

Submitted 27 May 2004. Accepted 25 November 2004. 